\title{
Comparison of 2 Lung Recruitment Strategies in Children With Acute Lung Injury
}

\author{
John N Kheir MD, Brian K Walsh RRT-NPS FAARC, Craig D Smallwood RRT-NPS, \\ Jordan S Rettig MD, John E Thompson RRT-NPS FAARC, Camille Gómez-Laberge PhD, \\ Gerhard K Wolf MD, and John H Arnold MD
}

\begin{abstract}
BACKGROUND: Lung recruitment maneuvers are frequently used in the treatment of children with lung injury. Here we describe a pilot study to compare the acute effects of $\mathbf{2}$ commonly used lung recruitment maneuvers on lung volume, gas exchange, and hemodynamic profiles in children with acute lung injury. METHODS: In a prospective, non-randomized, crossover pilot study, 10 intubated pediatric subjects with lung injury sequentially underwent: a period of observation; a sustained inflation (SI) maneuver of $40 \mathrm{~cm} \mathrm{H}_{2} \mathrm{O}$ for 40 seconds and open-lung ventilation; a staircase recruitment strategy (SRS) (which utilized $5 \mathrm{~cm} \mathrm{H}_{2} \mathrm{O}$ increments in airway pressure, from a starting plateau pressure of $30 \mathrm{~cm} \mathrm{H}_{2} \mathrm{O}$ and PEEP of $15 \mathrm{~cm} \mathrm{H} \mathrm{H}_{2} \mathrm{O}$ ); a downwards PEEP titration; and a 1 hour period of observation with PEEP set $2 \mathrm{~cm} \mathrm{H}_{2} \mathrm{O}$ above closing PEEP. RESULTS: Arterial blood gases, lung mechanics, hemodynamics, and functional residual capacity were recorded following each step of the study and following each increment of the SRS. Both SI and SRS were effective in raising $\mathrm{P}_{\mathrm{aO}}$ and functional residual capacity. During the SRS maneuver we noted significant increases in dead-space ventilation, a decrease in carbon dioxide elimination, an increase in $\mathrm{P}_{\mathrm{aCO}}$, and a decrease in compliance of the respiratory system. Lung recruitment was not sustained following the decremental PEEP titration. CONCLUSIONS: SRS is effective in opening the lung in children with early acute lung injury, and is hemodynamically well tolerated. However, attention must be paid to $\mathrm{P}_{\mathrm{aCO}}$ during the SRS. Even minutes following lung recruitment, lungs may derecruit when PEEP is lowered beyond the closing pressure. Key words: acute lung injury; ARDS; recruitment maneuver; functional residual capacity; staircase recruitment strategy. [Respir Care 2013;58(8):1280-1290. (C) 2013 Daedalus Enterprises]
\end{abstract}

\section{Introduction}

Acute lung injury (ALI) is a heterogeneous lung disease in which regions of diseased lung collapse in association with regional changes in lung surfactant, surface tension, and lung water. ${ }^{1}$ This leads to regions of intrapulmonary

Dr Kheir is affiliated with the Department of Cardiology; Dr Kheir, Mr Smallwood, Dr Gómez-Laberge, Dr Wolf, and Dr Arnold are affiliated with the Department of Anesthesiology, Perioperative and Pain Medicine; and Mr Walsh, Mr Smallwood, and Mr Thompson are affiliated with the Department of Respiratory Care, Boston Children's Hospital, Harvard Medical School, Boston, Massachusetts.

The authors have disclosed relationships with Abbott Point of Care, which provided the iStat blood gas analyzer; GE Healthcare, which provided the Engstrom Carestation; and Massimo, which provided the Radical-7 oximeter. shunting and hypoxemia. Decreases in aerated lung tissue may result from the weight of edematous lung $^{2}$ or from alveolar flooding. ${ }^{3}$ Regardless of the mechanism, it is agreed upon that increasing airway pressures are required to recruit these regions. Because lung disease is heterogeneous, compliant alveoli are aerated first, followed by diseased alveoli. Maneuvers designed to open the lung must be applied with sufficient pressure over sufficient time to reach diseased lung. Recruitment maneuvers (RMs) may be used to reverse episodes of profound hypoxemia, ap-

Correspondence: John N Kheir MD, Department of Cardiology, Boston
Children's Hospital, Harvard Medical School, 300 Longwood Avenue,
Bader 6, Boston MA 02115. E-mail: john.kheir@childrens.harvard.edu.

DOI: $10.4187 /$ respcare.01808 
plied empirically following periods of derecruitment (eg, suctioning), ${ }^{4}$ or utilized as part of a ventilation strategy. ${ }^{5}$

\section{See the Related Editorial on Page 1386}

Two lung RMs have been commonly described: sustained inflation (SI) and the staircase recruitment strategy (SRS). SI is produced by applying high CPAP (40$\left.50 \mathrm{~cm} \mathrm{H}_{2} \mathrm{O}\right)$ for a brief period of time $(30-40 \mathrm{~s})$. When combined with measures to maintain lung recruitment, SI raises $\mathrm{P}_{\mathrm{aO}}$ in patients with $\mathrm{ALI},{ }^{6}$ although this has not been shown to improve oxygen delivery or long-term outcomes. ${ }^{7-9}$ The SRS utilizes stepwise increases in plateau pressure and PEEP to recruit the lung gradually over time, and has demonstrated safety and efficacy in opening the lung in adult ${ }^{10-12}$ and pediatric ${ }^{13}$ patients with ALI. When compared to SI, SRS may impose less afterload on the right ventricle and less impairment of cardiac output. ${ }^{14,15}$ SI has been associated with temporary hemodynamic instability, desaturation, and agitation in pediatric patients, ${ }^{16}$ whereas SRS has been shown to be well tolerated in pediatric patients with ALI. ${ }^{13}$ In our ICU, patients with ALI are treated with SIs at the provider's discretion (eg, following suctioning or during a desaturation episode). We performed a pilot study of the safety and efficacy of SRS following SI in pediatric patients with ALI.

\section{Methods}

This study was approved by the institutional review board at Boston Children's Hospital. Our protocol was modified from that described by Borges, ${ }^{11}$ which included a sequential, non-randomized application of an SI and an open-lung approach, followed by application of an SRS. Although this precluded direct comparison of the 2 maneuvers, we viewed this primarily as a safety and feasibility study, and therefore adopted similar methodology.

\section{Subjects and Monitoring}

Patients admitted to the medical/surgical ICU at Boston Children's Hospital between October 1, 2008, and January 1, 2011, were screened for this study. Inclusion criteria included: 44 weeks post-conceptual age to 18 years old; met the criteria for $\mathrm{ALI}^{17}\left(\mathrm{P}_{\mathrm{aO}_{2}} / \mathrm{F}_{\mathrm{IO}_{2}}<300 \mathrm{~mm} \mathrm{Hg}\right.$ on arterial blood analysis obtained within $6 \mathrm{~h}$ of screening, acute onset of bilateral infiltrates on chest radiograph, and no evidence of left atrial hypertension); demonstrated apnea due to neuromuscular blockade or deep sedation; indwelling arterial line in situ; cuffed endotracheal tube in situ; conventional mechanical ventilation with current PEEP level between 5 and $15 \mathrm{~cm} \mathrm{H}_{2} \mathrm{O}$; and written parental consent obtained. Of note, we did not include spon-

\section{QUICK LOOK}

\section{Current knowledge}

Lung recruitment maneuvers improve oxygenation and lung compliance in patients with ARDS, but the effects are often transient, and hemodynamic complications are frequent.

\section{What this paper contributes to our knowledge}

In heavily sedated, well hydrated, pediatric patients, recruitment maneuvers improved oxygenation and were hemodynamically well tolerated. Hypercarbia was an important complication. Improvements in oxygenation were transient when PEEP was below the alveolar closing pressure.

taneously breathing patients in this study, as our institution's review board disapproved of administering additional sedative or neuromuscular blocking agents for this pilot study, stating that neuromuscular blocking agents are not part of standard practice for lung RMs, and therefore imposed an additional risk to subjects. Exclusion criteria were: met the criteria for ALI for $>72$ hours; active hemodynamic instability (defined as $>50 \%$ change in vasopressor dosing over the preceding $6 \mathrm{~h}$ ); history of prematurity (birth at post-conceptual age $<37$ weeks); clinically recognized airway disease; known congenital heart disease; congenital diaphragmatic hernia; recent history of intrathoracic instrumentation (eg, orthopedic instrumentation, cardiac pacemaker, thoracostomy); known restrictive lung disease, cystic fibrosis, or severe pulmonary hypertension, including patients on pulmonary vasodilator therapy); severe brain injury; or the use of extracorporeal life support.

Measured end points included heart rate, saturations, invasive arterial blood pressure, and central venous pressure, which were continuously monitored. At the end of each increment, vital signs, arterial blood gases (iStat $\mathrm{CG}^{+}$, Abbott Point of Care, Princeton, New Jersey), functional residual capacity (FRC) by multiple-breath nitrogen washout $^{18,19}$ (Engstrom Carestation, GE Healthcare, Madison, Wisconsin), static compliance of the respiratory system $\left(\mathrm{C}_{\mathrm{RS}}\right)$, and tidal volume $\left(\mathrm{V}_{\mathrm{T}}\right)$ were recorded. Deadspace ventilation (ratio of dead space $\left[\mathrm{V}_{\mathrm{D}}\right]$ to $\mathrm{V}_{\mathrm{T}}$ ) and elimination of carbon dioxide were also measured using a mainstream breath analyzer $\left(\mathrm{CO}_{2} \mathrm{SMO}\right.$ Plus, Respironics, Murrysville, Pennsylvania).

\section{Experimental Protocol}

All subjects were in the supine position, sedated, and received $\mathrm{F}_{\mathrm{IO}_{2}}$ of 1.0, except where specified. Prior to ini- 


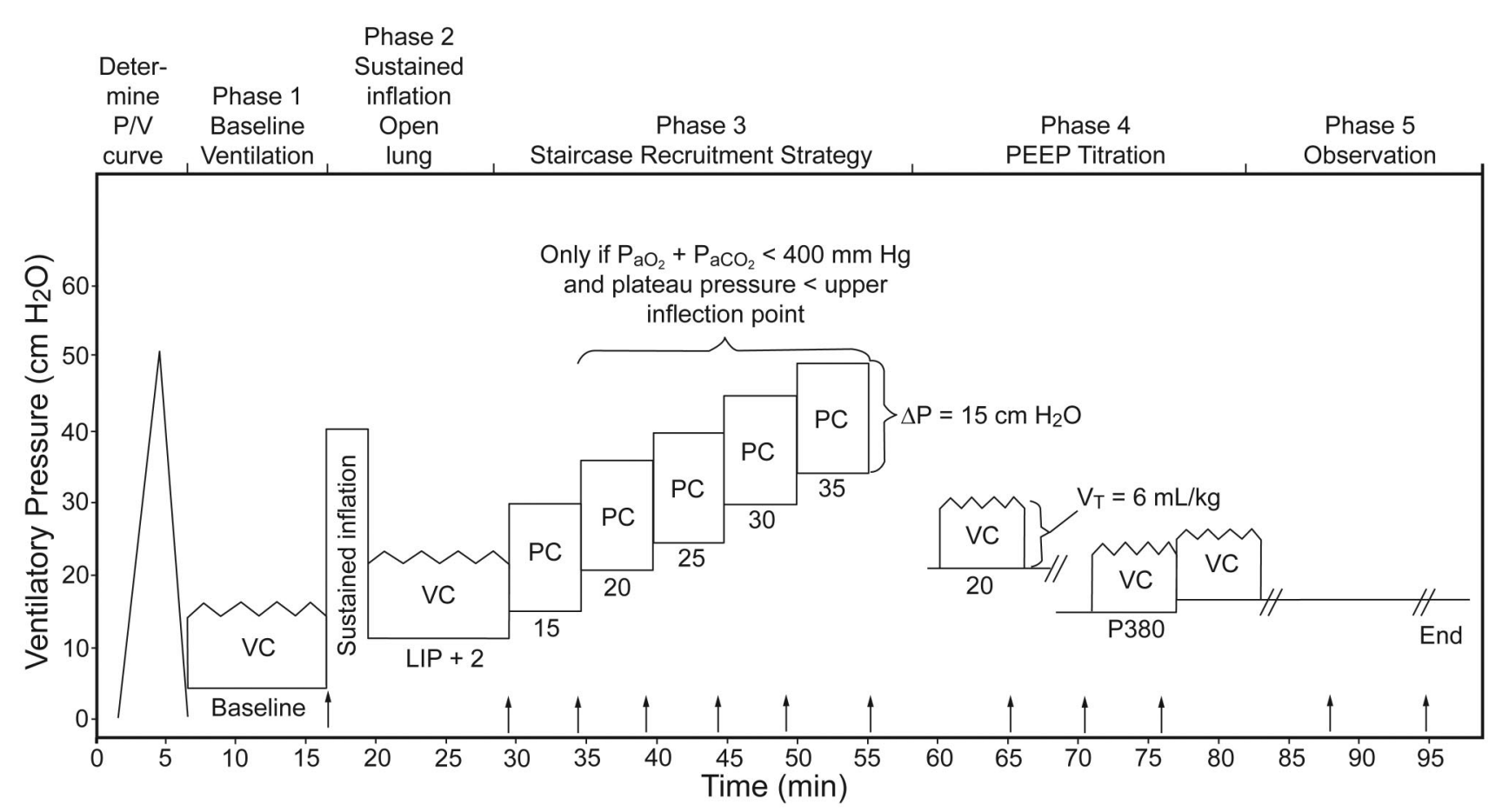

Fig. 1. Study protocol. Ventilation in step 1 (baseline ventilation), 2 (sustained inflation), 4 (PEEP titration), and 5 (observation) was with volume control (VC) ventilation. Step 3 used pressure control (PC) ventilation with a plateau pressure $15 \mathrm{~cm} \mathrm{H}_{2} \mathrm{O}$ above PEEP and the subject's baseline inspiratory time. End points were measured following each increment of each step (arrows). P380 denotes the PEEP increment at which $\mathrm{P}_{\mathrm{aO}_{2}}+\mathrm{P}_{\mathrm{acO}_{2}}$ was $<380 \mathrm{~mm} \mathrm{Hg}$.

tiation of the study, intravascular volume status was assessed by plethysmographic variability index (Radical-7 pulse oximeter, Masimo, Irvine, California)..$^{20,21}$ Subjects with a high plethysmographic variability index $(>15 \%)$ received a $5 \mathrm{~mL} / \mathrm{kg}$, one-time fluid bolus prior to subsequent interventions. The plethysmographic variability index was followed but not intervened upon thereafter. Subjects then underwent 3 pressure-volume curve determinations (Avea, Viasys Healthcare/Cardinal Health, Yorba Linda, California) for identification of upper and lower inflection points. When identified, the upper inflection point was set as the upper pressure limit for the subsequent steps of the study. Complete lung opening was defined as the sum of $\mathrm{P}_{a O_{2}}$ and $\mathrm{P}_{\mathrm{aCO}_{2}}$ exceeding $400 \mathrm{~mm} \mathrm{Hg}$ on an arterial blood sample. In adults with ARDS undergoing lung RMs, Borges et $\mathrm{al}^{11}$ found that subjects meeting this end point exhibited $<5 \%$ collapse of total lung mass, when studied by multi-slice computed tomography. All arterial blood samples were taken on $\mathrm{F}_{\mathrm{IO}_{2}}$ of 1.0. The 5 study steps (outlined in Fig. 1) were:

1. Baseline Ventilation. Subjects were observed on their baseline PEEP (ie, the set PEEP level at study enrollment) with volume control ventilation to achieve a $V_{T}$ of $6 \mathrm{~mL} / \mathrm{kg}$ ideal body weight (IBW) ${ }^{22}$ for $10 \mathrm{~min}$, followed by the measurements described above.
2. SI followed by open-lung ventilation strategy (SI). A CPAP of $40 \mathrm{~cm} \mathrm{H}_{2} \mathrm{O}$ was applied for 40 seconds, using a ventilator-delivered inspiratory hold maneuver. Upon completion of this maneuver, PEEP was set $2 \mathrm{~cm} \mathrm{H}_{2} \mathrm{O}$ above the lower inflection point, as previously identified on the pressure-volume curve. When a lower inflection point was not identified, PEEP was set $2 \mathrm{~cm} \mathrm{H}_{2} \mathrm{O}$ above baseline PEEP. Subjects were ventilated using volumecontrolled ventilation, using a $\mathrm{V}_{\mathrm{T}}$ of $6 \mathrm{~mL} / \mathrm{kg}$ IBW. Respiratory frequency was adjusted to ensure that measured minute ventilation was maintained as measured at baseline. This ventilation strategy was continued for $10 \mathrm{~min}$, followed by measurements.

3. SRS. Subjects were then placed in pressure-controlled ventilation with a plateau pressure of $15 \mathrm{~cm} \mathrm{H}_{2} \mathrm{O}$ above PEEP. Inspiratory time remained unchanged from baseline. PEEP was initially set at $15 \mathrm{~cm} \mathrm{H}_{2} \mathrm{O}$, which was maintained for $5 \mathrm{~min}$, followed by the measurements described above. If $\mathrm{P}_{\mathrm{aO}_{2}}$ plus $\mathrm{P}_{\mathrm{aCO}}$ was $<400 \mathrm{~mm} \mathrm{Hg}$, plateau pressure and PEEP were immediately increased by $5 \mathrm{~cm} \mathrm{H}_{2} \mathrm{O}$ and ventilation continued for another $5 \mathrm{~min}$, followed by repeated measurements. Measured minute ventilation was continually monitored, and respiratory frequency was adjusted to achieve the baseline measured minute ventilation as closely as possible. Inspiratory/ 
expiratory ratio was continuously monitored to ensure that it did not decrease below 1 ; if it did, the inspiratory time was adjusted to maintain the inspiratory/expiratory ratio above 1 . Spirometry was also examined to ensure that expiratory flow reached zero following each breath. Following each arterial blood sampling, respiratory frequency was further titrated as needed to maintain arterial $\mathrm{pH}>7.25$. The process was continued until either $\mathrm{P}_{\mathrm{aO}}$ plus $\mathrm{P}_{\mathrm{aCO}_{2}}$ exceeded $400 \mathrm{~mm} \mathrm{Hg}$, which represented complete lung opening, or plateau pressure reached either $50 \mathrm{~cm} \mathrm{H}_{2} \mathrm{O}$ or the measured upper inflection point (from the initial pressure-volume curve).

4. PEEP Titration. Following SRS, PEEP was instantaneously decreased to $20 \mathrm{~cm} \mathrm{H}_{2} \mathrm{O}$ with $\mathrm{V}_{\mathrm{T}}$ of $6 \mathrm{~mL} / \mathrm{kg}$ in volume-controlled ventilation. Following ventilation for $5 \mathrm{~min}$, end points were measured. Whenever the sum of $\mathrm{P}_{\mathrm{aO}_{2}}$ and $\mathrm{P}_{\mathrm{aCO}_{2}}$ exceeded $400 \mathrm{~mm} \mathrm{Hg}$, PEEP was decreased by $2 \mathrm{~cm} \mathrm{H}_{2} \mathrm{O}$ for $5 \mathrm{~min}$, followed by repeated measurements. Downward PEEP titration was continued until $\mathrm{P}_{\mathrm{aO}_{2}}+\mathrm{P}_{\mathrm{aCO}_{2}}$ was $<380 \mathrm{~mm} \mathrm{Hg}$ (suggesting that the lung had reached a closing pressure and begun the process of derecruitment ${ }^{11}$ ), at which point PEEP was increased and maintained $2 \mathrm{~cm} \mathrm{H}_{2} \mathrm{O}$ above closing PEEP for the 1-hour follow-up period. No attempts at repeating lung recruitment were made prior to this change.

5. Observation and Follow-up. PEEP was maintained at $2 \mathrm{~cm} \mathrm{H}_{2} \mathrm{O}$ above closing PEEP for $60 \mathrm{~min}$, with measurements taken at 30 and $60 \mathrm{~min}$, to evaluate maintenance of lung recruitment. Subjects were followed after completion of the protocol for 24 hours to monitor for development of pneumothorax or subcutaneous emphysema. Subject disposition was determined by subsequent chart review.

Criteria for aborting the study at any step included arterial $\mathrm{pH}$ below 7.00, decrease in mean arterial blood pressure by $20 \%$ or more, increase in vasoactive support by $>50 \%$, an arterial lactate $>2 \mathrm{mg} / \mathrm{dL}$, or a decrease in arterial saturation below $80 \%$.

\section{Data Management}

All ventilator data, arterial blood gases values, pulmonary mechanics, and FRC were hand recorded on data collection forms in real time, and subsequently entered into statistics software (Prism 5.0b, GraphPad Software, La Jolla, California) for analysis. Vital signs were stored by the hospital's electronic medical record system, and collected off-line for analysis. $\mathrm{P}_{\mathrm{aO}_{2}}$, FRC, and lung mechanics following each step were compared to baseline values using a Wilcoxon matched pairs test, except as noted. IBW was used for all weight-based calculations.

\section{Results}

During the study period, 58 patients with a definitive diagnosis of ALI (ie, had an arterial blood analysis demonstrating $\mathrm{P}_{\mathrm{aO}_{2}} / \mathrm{F}_{\mathrm{IO}_{2}}<300 \mathrm{~mm} \mathrm{Hg}$ ) were assessed for eligibility. Of these patients, 46 were excluded and 12 were enrolled (Fig. 2). One of these patients was then excluded due to the development of heart block during baseline observations, and a second was excluded because we discovered a small pneumothorax on the most recent chest $\mathrm{x}$-ray during the timeout immediately prior to the protocol. Therefore, 10 subjects completed the protocol (Table). The primary reason for exclusion was that patients were spontaneously breathing. Others included prematurity $(<37$ weeks gestational age), known restrictive lung disease, severe reactive airways disease, age $>18$ years, air leak or presence of a thoracostomy tube, team member unavailability, hemodynamic criteria, unilateral pneumonia, pleural or pericardial effusions, $\mathrm{PEEP}>16 \mathrm{~cm} \mathrm{H}_{2} \mathrm{O}$, primary pulmonary hypertension, and tracheomalacia.

Of the 10 subjects completing the protocol, all completed step 1 of the SRS (PEEP $15 \mathrm{~cm} \mathrm{H}_{2} \mathrm{O}, \Delta$ pressure $15 \mathrm{~cm} \mathrm{H}_{2} \mathrm{O}$ ). Subsequently, one subject exited the protocol due to severe respiratory acidosis, which was a stopping criteria for the study, and 2 others met criteria for lung opening (ie, $\mathrm{P}_{\mathrm{aO}_{2}}+\mathrm{P}_{\mathrm{aCO}_{2}} \geq 400 \mathrm{~mm} \mathrm{Hg}$ ). Seven subjects completed step 2 of the SRS (PEEP $20 \mathrm{~cm} \mathrm{H}_{2} \mathrm{O}$ ), and one of these subsequently met criteria for lung opening. Six subjects completed step 3 (PEEP $25 \mathrm{~cm} \mathrm{H}_{2} \mathrm{O}$ ), none of whom then met criteria for lung opening. Six subjects completed step 4 (PEEP $30 \mathrm{~cm} \mathrm{H}_{2} \mathrm{O}$ ), 2 of whom subsequently met criteria for lung opening, and one did not go on to step 5 because this would have exceeded the measured upper inflection point. Three subjects completed step 5 (PEEP $35 \mathrm{~cm} \mathrm{H}_{2} \mathrm{O}$ ), 2 of whom subsequently met criteria for lung opening, and the third did not. Therefore, of the 10 children studied, 7 achieved complete lung recruitment, and all of these were discharged from the hospital. Three remaining subjects failed to achieve complete lung recruitment: the subject who completed the 5 steps of the SRS without achieving lung opening was discharged from the hospital. The subject who exited the protocol following step 4 due to the measured upper inflection point died several days later. The third subject who exited the SRS following step 1, due to severe respiratory acidosis, died several days later. Except for the subject who met stopping criteria (respiratory acidosis), all subjects $(n=9)$ completed the PEEP titration and observation steps of the protocol.

\section{Efficacy of RMs}

$\mathrm{P}_{\mathrm{aO}_{2}}$ at the end of the SRS step $(383 \mathrm{~mm} \mathrm{Hg}, 95 \% \mathrm{CI}$ $247-519 \mathrm{~mm} \mathrm{Hg}$ ) was significantly higher than baseline 


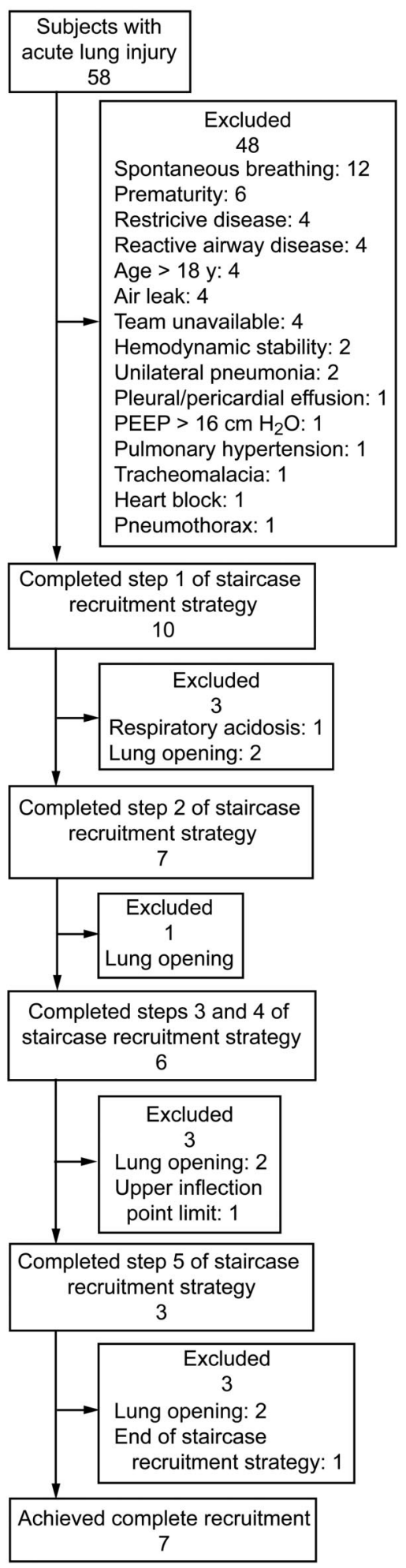

Fig. 2. Flow diagram of patients with acute lung injury admitted to the ICU during study period. Of the subjects who were enrolled, subjects were excluded for meeting stopping criteria or maximal lung opening. Subjects who met stopping criteria were returned to pre-trial ventilator settings and observed. Subjects in whom maximal lung opening criteria were obtained underwent PEEP titration and observational phases.
(226 mm Hg, 95\% CI 113-339 mm Hg, $P=.02$ ), and nonsignificantly higher than following SI $(261 \mathrm{~mm} \mathrm{Hg}$, $95 \%$ CI $128-395 \mathrm{~mm} \mathrm{Hg}, P=.055) . \mathrm{P}_{\mathrm{aO}_{2}}$ following SI was also significantly higher than baseline $(P=.01)$. Following the decrease in airway pressure at the end of SRS, $\mathrm{P}_{\mathrm{aO}}$ increased further during the first several steps of the PEEP titration step (Fig. 3). $\mathrm{P}_{\mathrm{aO}_{2}}$ subsequently decreased with downward titration of PEEP throughout the PEEP titration step, and was not different from baseline values during the observation step.

FRC following SI was nonsignificantly higher than baseline $(18.6 \mathrm{~mL} / \mathrm{kg}$ IBW during SI vs $14.6 \mathrm{~mL} / \mathrm{kg}$ IBW at baseline, $P=.055)$, but increased significantly, to $34.8 \mathrm{~mL} / \mathrm{kg} \mathrm{IBW}$ at the end of SRS $(P=.02)$. In contrast to the increase in $\mathrm{P}_{\mathrm{aO}_{2}}$ during the initial steps of the PEEP titration, FRC decreased to a plateau early in the PEEP titration step, which was not significantly different from baseline values.

\section{Safety of RMs}

Three subjects received a one-time, $5 \mathrm{~mL} / \mathrm{kg}$ fluid bolus for plethysmographic variability index $>15 \%$ prior to entering the protocol. One subject exited the protocol due to severe respiratory acidosis and mild hypotension during the first step of the SRS step. This subject was placed on high frequency oscillatory ventilation, then extracorporeal membrane oxygenation, and subsequently died of respiratory failure. Two subjects experienced desaturation at the end of the SI procedure, which resolved spontaneously upon the release of the maneuver. Two subjects exhibited tachycardia without hypotension during the SI, which resolved at the end of the maneuver. There were no episodes of desaturation, tachycardia, or hypotension associated with SRS. There were no statistically significant differences in heart rate and mean arterial blood pressure during the recruitment protocol (Fig. 4). Central venous pressure transiently increased during the later steps of the SRS. There were no episodes of pneumothorax or subcutaneous emphysema.

$\mathrm{P}_{\mathrm{aCO}_{2}}$ increased throughout SRS $(46.1 \mathrm{~mm} \mathrm{Hg}, 95 \% \mathrm{CI}$ $41.1-51.2 \mathrm{~mm} \mathrm{Hg}$ ), from the first step of SRS, to $64.3 \mathrm{~mm} \mathrm{Hg}, 95 \% \mathrm{CI} 48.6-80.0 \mathrm{~mm} \mathrm{Hg}$, at maximal lung opening $(P=.01$ via Mann-Whitney test), but was not associated with a significant change in arterial $\mathrm{pH}(P=.35)$ (Fig. 5). As the subjects progressed through the SRS step, there were significant increases in $\mathrm{V}_{\mathrm{D}} / \mathrm{V}_{\mathrm{T}}$. Immediately upon release of airway pressure at the end of SRS (mean PEEP decreased from 27 to $18 \mathrm{~cm} \mathrm{H}_{2} \mathrm{O}$ ), $\mathrm{V}_{\mathrm{D}} / \mathrm{V}_{\mathrm{T}}$ decreased to values similar to baseline. Similarly, carbon dioxide elimination decreased significantly as the subjects progressed through SRS $(P=.007$ via linear regression), and was lower during the final step of SRS $(67.9 \mathrm{~mL} \mathrm{CO} /$ $\mathrm{min} / \mathrm{kg} \mathrm{IBW}, 95 \%$ CI $28.4-107.4 \mathrm{~mL} \mathrm{CO} / \mathrm{min} / \mathrm{kg} \mathrm{IBW}$ ) 
Table. Subject Factors Upon Meeting Inclusion Criteria

\begin{tabular}{|c|c|c|c|c|c|c|c|c|c|c|}
\hline $\begin{array}{l}\text { Patient } \\
\text { Number }\end{array}$ & Sex & $\begin{array}{l}\text { Age } \\
(y)\end{array}$ & $\begin{array}{r}\text { IBW } \\
(\mathrm{kg})\end{array}$ & Diagnosis & $\begin{array}{l}\text { Etiology of Acute } \\
\text { Lung Injury }\end{array}$ & $\mathrm{F}_{\mathrm{IO}_{2}}$ & $\begin{array}{l}\mathrm{P}_{\mathrm{aO}_{2}} / \mathrm{F}_{\mathrm{IO}_{2}} \\
\left(\mathrm{~mm} \mathrm{Hg}^{*}\right)\end{array}$ & $\begin{array}{c}\text { PEEP } \\
\left(\mathrm{cm} \mathrm{H} \mathrm{H}_{2} \mathrm{O}\right)\end{array}$ & $\begin{array}{c}\mathrm{C}_{\mathrm{RS}} \\
\left(\mathrm{mL} / \mathrm{cm} \mathrm{H}_{2} \mathrm{O} / \mathrm{kg}\right. \\
\mathrm{IBW})\end{array}$ & $\begin{array}{c}\text { Oxygenation } \\
\text { Index } \dagger\end{array}$ \\
\hline 1 & $\mathrm{~F}$ & 5.9 & 20 & Parainfluenza pneumonia & Pulmonary & 0.7 & 87 & 12 & 0.71 & 16.1 \\
\hline 2 & M & 4.2 & 16.2 & Kawasaki syndrome & Non-pulmonary & 1 & 65 & 12 & 0.37 & 27.7 \\
\hline 3 & $\mathrm{~F}$ & 10.2 & 13.9 & Sepsis, ascites & Non-pulmonary & 0.6 & 192 & 12 & 0.45 & 8.9 \\
\hline 4 & $\mathrm{~F}$ & 5.6 & 34 & Sepsis & Non-pulmonary & 0.5 & 224 & 8 & 0.44 & 6.7 \\
\hline 5 & $\mathrm{~F}$ & 10.4 & 38.5 & Necrotizing pneumonia & Pulmonary & 0.6 & 123 & 14 & 0.21 & 17.0 \\
\hline 6 & $\mathrm{~F}$ & 13.9 & 54.7 & Sepsis & Pulmonary & 0.6 & 123 & 14 & 0.33 & 22.7 \\
\hline 7 & $\mathrm{~F}$ & 17.3 & 73.1 & Macrophage activation syndrome & Non-pulmonary & 0.7 & 201 & 10 & 0.47 & 7.0 \\
\hline 8 & $\mathrm{~F}$ & 4.9 & 18.2 & Respiratory syncytial virus pneumonitis & Pulmonary & 1 & 60 & 15 & 0.50 & 30.0 \\
\hline 9 & M & 11.7 & 43.1 & Sepsis & Non-pulmonary & 0.4 & 268 & 12 & 0.47 & 6.4 \\
\hline 10 & $\mathrm{~F}$ & 9.4 & 38.5 & Trauma & Non-pulmonary & 0.4 & 188 & 10 & 0.36 & 8.0 \\
\hline \multicolumn{11}{|c|}{$\begin{array}{l}{ }^{*} \mathrm{P}_{\mathrm{aO}} / \mathrm{F}_{\mathrm{IO}} \text { upon meeting inclusion criteria. } \\
\dagger \mathrm{xygenation} \text { index }=\mathrm{F}_{\mathrm{IO}_{2}} \times \text { mean airway pressure/ } \mathrm{P}_{\mathrm{aO}} \mathrm{O}_{2} \\
\ddagger \mathrm{This} \text { patient with respiratory syncytial virus did not exhibit signs of airways disease by spirometry. } \\
\mathrm{IBW}=\text { ideal body weight } \\
\mathrm{C}_{\mathrm{RS}}=\text { compliance of the respiratory system }\end{array}$} \\
\hline
\end{tabular}

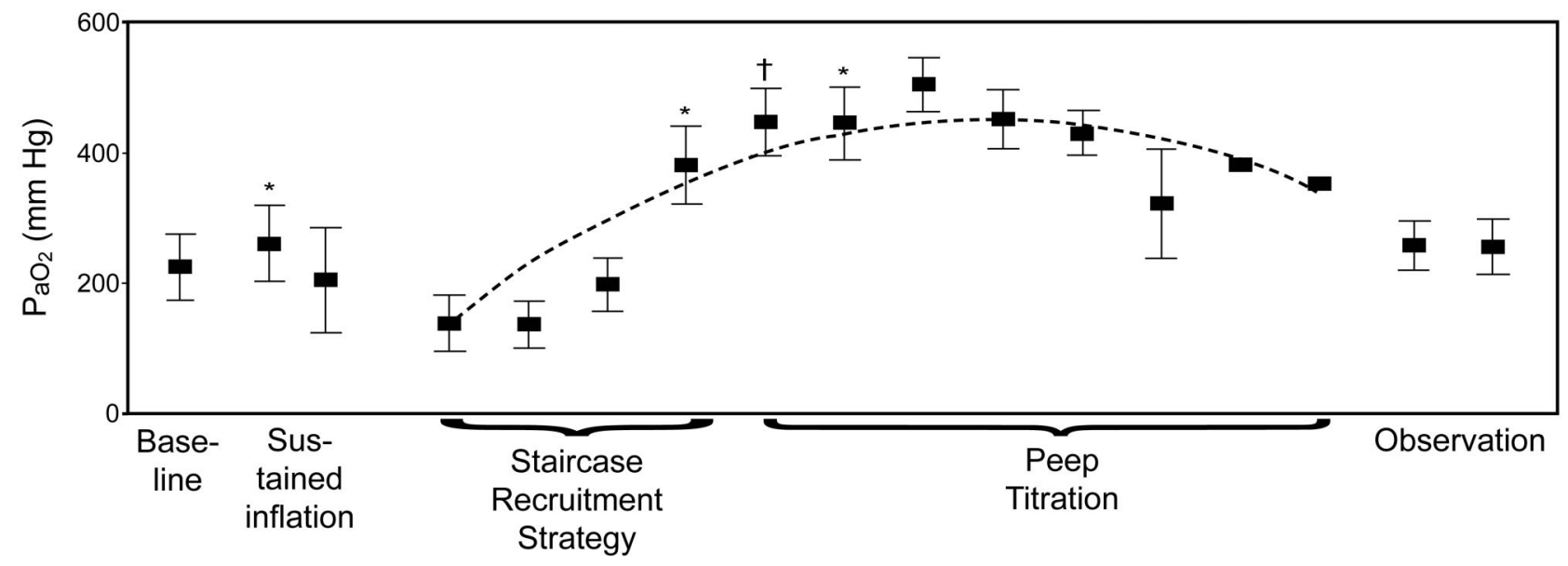

Fig. 3. Efficacy of recruitment maneuvers: $\mathrm{P}_{a_{2}}$ (on $\mathrm{F}_{\mathrm{IO}_{2}}$ of 1.0) increased relative to baseline following a single sustained inflation. As subjects progressed through the staircase recruitment strategy steps of increasing airway pressure, $\mathrm{P}_{\mathrm{aO}}$ initially decreased, then significantly increased. $\mathrm{P}_{\mathrm{aO}_{2}}$ increased further during the first 3 PEEP titration steps, then decreased to near-baseline as PEEP was decreased to below the closing pressure, and maintained there during the observation step. Comparisons drawn between step shown and baseline, using Wilcoxon matched pairs test. The dotted line represents the quadratic polynomial regression line. ${ }^{*} P<.05, \dagger P=.001$. The error bars represent the standard error of the mean.

than following SI $(109.4 \mathrm{~mL} \mathrm{CO} / \mathrm{min} / \mathrm{kg} \mathrm{IBW,} \mathrm{95 \%} \mathrm{CI}$ $68.5-150.4 \mathrm{~mL} \mathrm{CO} / \mathrm{min} / \mathrm{kg} \mathrm{IBW}, P=.03$ via Wilcoxon signed rank test) (see Fig. 4). $\dot{\mathrm{V}}_{\mathrm{CO}_{2}}$ during the SRS reached as low as $2 \mathrm{~mL} / \mathrm{min} / \mathrm{kg}$ in one subject, and $11 \mathrm{~mL} / \mathrm{min} / \mathrm{kg}$ in another, both during the final step of SRS. These changes were paralleled by a decrease in $C_{R S}$ and $V_{T}$ throughout the SRS step, all of which normalized with release of airway pressure during the PEEP titration step. In response to decreases in $\mathrm{V}_{\mathrm{T}}$, respiratory frequency was significantly increased, to $124 \%, 95 \%$ CI $112-135 \%$, of baseline by the end of the SRS.

\section{Discussion}

Our results suggest that in ventilated pediatric patients with ALI: both SI and SRS effectively raise $\mathrm{P}_{\mathrm{aO}}$ and FRC; SI may be associated with temporary desaturation in children; SRS is associated with an increase in $\mathrm{P}_{\mathrm{aCO}}$ during the maneuver; and both SI and SRS are hemodynamically well tolerated.

Several studies have noted that both SI and SRS are effective in raising $\mathrm{P}_{\mathrm{aO}_{2}}$ in adults and children with ARDS.7,11,13,23 When an SRS was applied following an SI, 


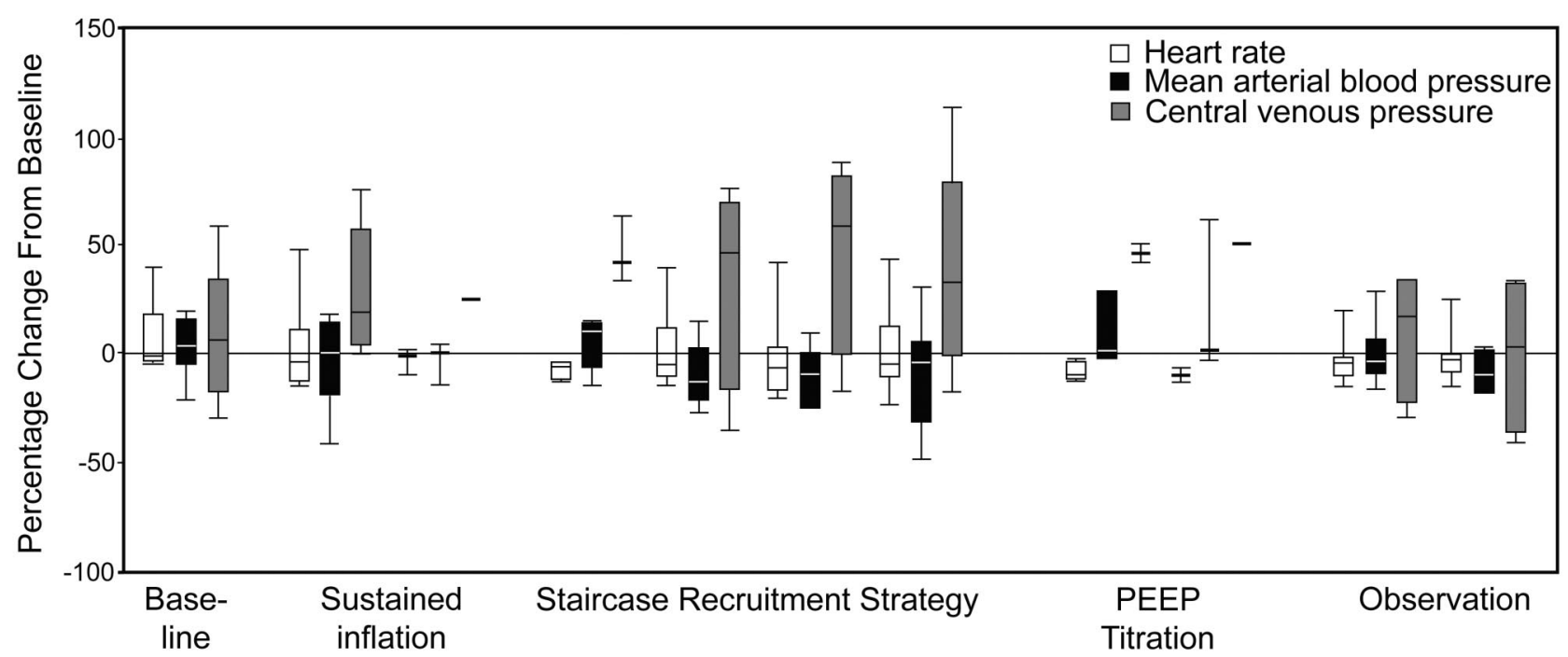

Fig. 4. Percent change from baseline in heart rate, mean arterial blood pressure, and central venous pressure. There were no significant changes in heart rate or mean arterial blood pressure. Central venous pressure increased during the later staircase recruitment strategy steps, which correlated with a similar trend in mean airway pressure. For simplicity, only the first 2 PEEP titration steps are shown. The horizontal line within each data bar represents the median, the tops and bottoms of the data bars represent the interquartile range, and the whiskers represent the range.

in non-randomized fashion, Borges et all ${ }^{11}$ noted that $\mathrm{P}_{\mathrm{aO}}$ rose further following SRS. When assessed using computed tomography, Borges et al also noted regions of lung collapse that had not opened following SI became aerated following SRS. This is consistent with the increase in FRC we demonstrated following SRS, compared to following SI. However, in both the Borges et al study and our study, the non-randomized, sequential application of SRS after an SI precludes any conclusions regarding the efficacy of one maneuver over the other; it is possible that serial applications of SI could have a similar effect.

The increase in $\mathrm{P}_{\mathrm{aO}_{2}}$ following lung recruitment was not sustained in our study using a modification of the PEEP titration described by Borges et al. ${ }^{11}$ It has been demonstrated in both adults ${ }^{24}$ and children ${ }^{13}$ that, in order to sustain improvements in oxygenation following RMs, PEEP must be optimized following the completion of the RM. In our protocol we weaned PEEP following SRS until we found evidence on arterial blood gas of partial lung "closing" (ie, that the $\mathrm{P}_{\mathrm{aO}}$ plus $\mathrm{P}_{\mathrm{aCO}_{2}}$ decreased to below $380 \mathrm{~mm} \mathrm{Hg}$, which most likely represented a decrease in PEEP below the critical closing pressure of the lung). Because we did not then take measures to re-recruit the lung following this step, it was not surprising that the improvement in oxygenation was no longer sustained. Following a similar stepwise RM followed by downward PEEP titration, Boriosi et $\mathrm{al}^{13}$ found that the addition of a "rerecruitment" maneuver (ventilation at "opening pressures for 2 min," ie, the highest step used during the SRS) af- forded an improvement in $\mathrm{P}_{\mathrm{aO}} / \mathrm{F}_{\mathrm{IO}_{2}}$, which persisted up to 12 hours post RM.

Consistent with prior reports, ${ }^{13,25}$ subjects tolerated the SI with only transient desaturation, and did not exhibit significant hemodynamic changes during SRS. However, one very important potential adverse effect of SRS is severe hypercarbia during the maneuver itself. Boriosi et al ${ }^{13}$ described a protocol in children similar to the SRS described here, though they utilized similar airway pressures (peak pressures of $45 \mathrm{vs} 50 \mathrm{~cm} \mathrm{H}_{2} \mathrm{O}$ ) over substantially shorter periods ( $1 \mathrm{~min}$ vs $10 \mathrm{~min}$ per step), and did not measure arterial blood gases during the SRS itself. They described an initial cohort of subjects who developed hypercarbia following the SRS, and they modified the SRS to include a minimum $\mathrm{V}_{\mathrm{T}}$ of $4 \mathrm{~mL} / \mathrm{kg}$, increased respiratory frequency during the maneuver, and a stopping rule for increases in end-tidal $\mathrm{CO}_{2}$. They also excluded patients with preexisting respiratory acidosis from enrollment. With these modifications the authors did not report significant changes in $\mathrm{P}_{\mathrm{aCO}}$ immediately following the SRS.

Our protocol did not include such modifications, though we carefully monitored arterial blood gases, minute ventilation, and carbon dioxide elimination during each increment of the SRS. Although respiratory frequency was increased in most subjects as they progressed through the SRS to maintain near-baseline measured minute ventilation, we still noted significant increases in $\mathrm{P}_{\mathrm{aCO}}$ and decreases in carbon dioxide elimination during the SRS. However, only 2 subjects (one subject with hypercarbia and 

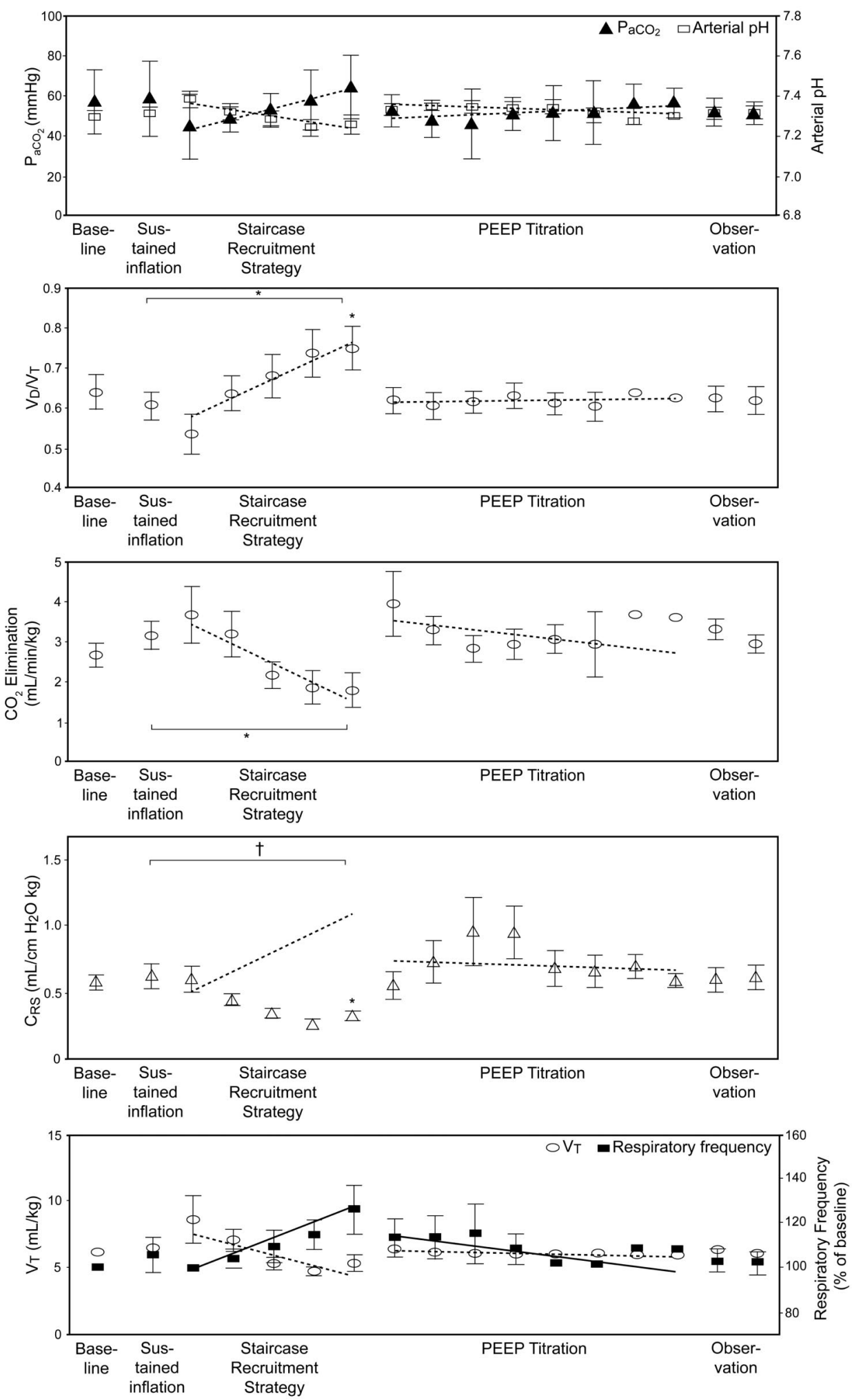

Fig. 5. $\mathrm{P}_{\mathrm{aCO}}$, arterial pH, ratio of dead space $\left(\mathrm{V}_{\mathrm{D}}\right)$ to tidal volume $\left(\mathrm{V}_{\mathrm{T}}\right)$, carbon dioxide elimination $\left(\dot{\mathrm{V}}_{\mathrm{CO}_{2}}\right)$, respiratory-system compliance $\left(\mathrm{C}_{\mathrm{RS}}\right)$, $\mathrm{V}_{\mathrm{T}}$, and respiratory frequency. During the staircase recruitment strategy steps, $\mathrm{P}_{\mathrm{acO}_{2}}$ increased $(P=.01)$, arterial pH did not significantly decrease, $\mathrm{V}_{\mathrm{D}} \mathrm{V}_{\mathrm{T}}$ increased $(P=.01)$, elimination of carbon dioxide decreased $(P=.007), \mathrm{C}_{\mathrm{RS}}$ decreased $(P<.001), \mathrm{V}_{\mathrm{T}}$ decreased $(P=.005)$, and respiratory frequency (expressed as a percentage of baseline) increased $(P=.03)$. * Differences between baseline, sustained inflation, and the final staircase recruitment strategy step via Wilcoxon matched pairs test: $P<.05$. † Changes during staircase recruitment strategy via linear regression: $P<.01$. The error bars represent the standard error of the mean. The dotted lines represent the linear regression lines. 
one subject with an upper inflection point boundary) met predefined stopping rules that precluded completion of the SRS maneuver. In subjects in whom $\mathrm{P}_{\mathrm{aCO}}$ is not closely monitored, the safety of SRS may be compromised. Because the mechanism of hypercarbia in this setting may be an increase in $\mathrm{V}_{\mathrm{D}} / \mathrm{V}_{\mathrm{T}}$, it is possible that monitoring of end-tidal $\mathrm{CO}_{2}$ alone may be insufficient. Safety of the maneuver may be further enhanced by utilizing regular recovery periods at lower pressures (as utilized by Borges et $\mathrm{al}^{11}$ ), utilizing lower airway pressures for shorter durations, ${ }^{13,26}$ or by use of a larger driving pressure (peak inspiratory pressure minus PEEP) during the maneuver. The use of esophageal pressure monitoring to quantify transpulmonary pressure 27 may also enhance the safety profile of SRS.

\section{Limitations}

This was a single institution study, and our sample size was restricted by the requirement for an indwelling arterial line and apnea due to sedation or neuromuscular blockade. During the study period, most intubated patients with ALI were kept spontaneously breathing and were monitored noninvasively (ie, without an arterial line), thus excluding them from study.

Because our subjects were heavily sedated or receiving neuromuscular blockade, we did not experience problems with agitation or ventilator asynchrony during either SI or SRS. Therefore, the safety of the SRS maneuver described here cannot be applied broadly to patients who are less sedate and/or breathing spontaneously. This represents one important area of future research before SRS can be applied broadly to the pediatric population.

As mentioned above, the study protocol was modified from one previously described, ${ }^{11}$ in which subjects were exposed first to an SI, followed by an open-lung approach, and then to a similar SRS (which utilized higher airway pressures). Although the authors concluded that "the proposed maximum-recruitment strategy recruited the lung significantly better than the open-lung approach," the sequential, non-randomized fashion in which both experiments were performed precludes any conclusions regarding the efficacy of one technique over the other. In our protocol, subjects received several RMs in series (including 3 pressure/volume curve measurements, SI, and SRS), which likely had a cumulative hysteretic effect. As the SRS was performed last in the experimental protocol, the positive results may be biased by this sequence effect. Further, the measurements of lung opening following the SI were performed following a $5 \mathrm{~min}$ period of "open-lung ventilation." Although this approach (at least theoretically) prevented lung derecruitment during open-lung approach ventilation, by maintaining PEEP above the lower inflection point, the measurements were completed on ventilating settings (rather than recruitment settings, as in the SRS), which precludes comparison of the 2 maneuvers.

We examined only for short-term hemodynamic effects. If RMs are performed regularly (eg, as part of a ventilation protocol), they may lead to cumulative air trapping that could cause hemodynamic compromise.

Our study criteria excluded patients not adequately resuscitated or with active hemodynamic instability. Our protocol also included steps to optimize intravascular volume, using an objective monitor of intravascular volume status. The safety of SI or SRS in hemodynamically unstable patients is, therefore, unknown.

The presence of ventilator-associated lung injury related to the protocol cannot be completely ruled out, though the absence of air leak as a result of the protocol was reassuring.

Finally, we studied the efficacy of lung opening in subjects within 72 hours of the diagnosis of ALI. Several authors have suggested that lung recruitment in later stages may be less effective. ${ }^{28-30}$

In the majority of our subjects we noted a sequence of events associated with lung recruitment. As subjects approached the critical opening pressure during SRS, $\mathrm{V}_{\mathrm{T}}$ decreased, $\mathrm{C}_{\mathrm{RS}}$ decreased, and carbon dioxide elimination decreased, at times dramatically. It is possible that in order to recruit densely consolidated lung, compliant alveoli must be markedly overdistended (and thus rendered less compliant) in order to open less compliant regions. In doing so, perfusion to more compliant regions decreases, ${ }^{31}$ which increases $\mathrm{V}_{\mathrm{D}} / \mathrm{V}_{\mathrm{T}}$ and carbon dioxide elimination, and decreases $\mathrm{C}_{\mathrm{RS}}{ }^{32}$ This phenomenon also shunts pulmonary blood flow from compliant alveoli toward less compliant regions (which presumably exhibit a higher alveolar-arterial oxygen difference), which may further increase intrapulmonary shunting. We hypothesize that oxygenation improves when diseased, poorly compliant regions are recruited during the SRS, and improves further as airway pressures are released and perfusion to healthy alveoli is restored.

Many questions remain regarding the utility of RMs in the care of patients with ALI. The ability of RMs to impact patient outcome (eg, ventilator-free days or mortality) has not been demonstrated in either adult or pediatric populations. ${ }^{33}$ Before these clinical trials can be appropriately designed, the safety of the SRS should be studied in a larger cohort of children (ideally stratified by severity of lung injury), and the SRS and SI should be compared in randomized fashion. Finally, the ability of RMs to achieve substantial lung recruitment in the later stages of ALI should be examined. 


\section{Comparison of 2 Lung Recruitment Strategies in Children With Acute Lung Injury}

\section{Conclusions}

In heavily sedated, volume-replete pediatric patients, both SI and SRS appear to be hemodynamically well tolerated. Both SRS and SI are effective in immediately raising $\mathrm{P}_{\mathrm{aO}_{2}}$. Hypercarbia is an important risk of SRS, which requires caution in clinical use and merits further study. When followed by decremental PEEP titration without attempts at lung re-recruitment, the lung recruiting effects of the SRS were transient.

\section{REFERENCES}

1. Ranieri VM, Rubenfeld GD, Thompson BT, Ferguson ND, Caldwell E, Fan E, et al. Acute respiratory distress syndrome: the Berlin Definition. JAMA 2012;307(23):2526-2533.

2. Gattinoni L, D'Andrea L, Pelosi P, Vitale G, Pesenti A, Fumagalli R. Regional effects and mechanism of positive end-expiratory pressure in early adult respiratory distress syndrome. JAMA 1993;269(16): 2122-2127.

3. Hubmayr RD. Perspective on lung injury and recruitment: a skeptical look at the opening and collapse story. Am J Respir Crit Care Med 2002;165(12):1647-1653

4. Constantin JM, Futier E, Cherprenet AL, Chanques G, Guerin R, Cayot-Constantin S, et al. A recruitment maneuver increases oxygenation after intubation of hypoxemic intensive care unit patients: a randomized controlled study. Crit Care 2010;14(2):R76.

5. Heinze H, Eichler W, Karsten J, Sedemund-Adib B, Heringlake M, Meier T. Functional residual capacity-guided alveolar recruitment strategy after endotracheal suctioning in cardiac surgery patients. Crit Care Med 2011;39(5):1042-1049.

6. Toth I, Leiner T, Mikor A, Szakmany T, Bogar L, Molnar Z. Hemodynamic and respiratory changes during lung recruitment and descending optimal positive end-expiratory pressure titration in patients with acute respiratory distress syndrome. Crit Care Med 2007; 35(3):787-793

7. Foti G, Cereda M, Sparacino ME, De Marchi L, Villa F, Pesenti A. Effects of periodic lung recruitment maneuvers on gas exchange and respiratory mechanics in mechanically ventilated acute respiratory distress syndrome (ARDS) patients. Intensive Care Med 2000;26(5): 501-507.

8. Meade MO, Cook DJ, Guyatt GH, Slutsky AS, Arabi YM, Cooper DJ, et al. Ventilation strategy using low tidal volumes, recruitment maneuvers, and high positive end-expiratory pressure for acute lung injury and acute respiratory distress syndrome: a randomized controlled trial. JAMA 2008;299(6):637-645.

9. Tugrul S, Akinci O, Ozcan PE, Ince S, Esen F, Telci L, et al. Effects of sustained inflation and postinflation positive end-expiratory pressure in acute respiratory distress syndrome: focusing on pulmonary and extrapulmonary forms. Crit Care Med 2003;31(3):738-744.

10. Povoa P, Almeida E, Fernandes A, Mealha R, Moreira P, Sabino H. Evaluation of a recruitment maneuver with positive inspiratory pressure and high PEEP in patients with severe ARDS. Acta Anaesthesiol Scand 2004;48(3):287-293.

11. Borges JB, Okamoto VN, Matos GF, Caramez MP, Arantes PR, Barros F, et al. Reversibility of lung collapse and hypoxemia in early acute respiratory distress syndrome. Am J Respir Crit Care Med 2006;174(3):268-278.

12. Morán I, Blanch L, Fernández R, Fernández-Mondéjar E, Zavala E, Mancebo J. Acute physiologic effects of a stepwise recruitment maneuver in acute respiratory distress syndrome. Minerva Anestesiol 2011;77(12):1167-1175.
13. Boriosi JP, Sapru A, Hanson JH, Asselin J, Gildengorin G, Newman $\mathrm{V}$, et al. Efficacy and safety of lung recruitment in pediatric patients with acute lung injury. Pediatr Crit Care Med 2011;12(4):431-436.

14. Lim SC, Adams AB, Simonson DA, Dries DJ, Broccard AF, Hotchkiss JR, et al. Transient hemodynamic effects of recruitment maneuvers in three experimental models of acute lung injury. Crit Care Med 2004;32(12):2378-2384.

15. Iannuzzi M, De Sio A, De Robertis E, Piazza O, Servillo G, Tufano R. Different patterns of lung recruitment maneuvers in primary acute respiratory distress syndrome: effects on oxygenation and central hemodynamics. Minerva Anestesiol 2010;76(9):692-698.

16. Duff JP, Rosychuk RJ, Joffe AR. The safety and efficacy of sustained inflations as a lung recruitment maneuver in pediatric intensive care unit patients. Intensive Care Med 2007;33(10):1778-1786.

17. Bernard GR, Artigas A, Brigham KL, Carlet J, Falke K, Hudson L, et al. Report of the American-European consensus conference on ARDS: definitions, mechanisms, relevant outcomes and clinical trial coordination. The Consensus Committee. Intensive Care Med 1994; 20(3):225-232.

18. Olegard C, Sondergaard S, Houltz E, Lundin S, Stenqvist O. Estimation of functional residual capacity at the bedside using standard monitoring equipment: a modified nitrogen washout/washin technique requiring a small change of the inspired oxygen fraction. Anesth Analg 2005;101(1):206-212.

19. Zinserling J, Wrigge H, Varelmann D, Hering R, Putensen C. Measurement of functional residual capacity by nitrogen washout during partial ventilatory support. Intensive Care Med 2003;29(5):720-726.

20. Natalini G, Rosano A, Taranto M, Faggian B, Vittorielli E, Bernardini A. Arterial versus plethysmographic dynamic indices to test responsiveness for testing fluid administration in hypotensive patients: a clinical trial. Anesth Analg 2006;103(6):1478-1484

21. Feissel M, Teboul JL, Merlani P, Badie J, Faller JP, Bendjelid K. Plethysmographic dynamic indices predict fluid responsiveness in septic ventilated patients. Intensive Care Med 2007;33(6):993-999.

22. The Acute Respiratory Distress Syndrome Network. Ventilation with lower tidal volumes as compared with traditional tidal volumes for acute lung injury and the acute respiratory distress syndrome. N Engl J Med 2000;342(18):1301-1308.

23. Villagrá A, Ochagavia A, Vatua S, Murias G, Del Mar Fernández M, Lopez Aguilar J, et al. Recruitment maneuvers during lung protective ventilation in acute respiratory distress syndrome. Am J Respir Crit Care Med 2002;165(2):165-170.

24. Lim CM, Jung H, Koh Y, Lee JS, Shim TS, Lee SD, et al. Effect of alveolar recruitment maneuver in early acute respiratory distress syndrome according to antiderecruitment strategy, etiological category of diffuse lung injury, and body position of the patient. Crit Care Med 2003;31(2):411-418.

25. Iannuzzi M, De Sio A, De Robertis E, Piazza O, Servillo G, Tufano R. Different patterns of lung recruitment maneuvers in primary acute respiratory distress syndrome: effects on oxygenation and central hemodynamics. Minerva Anestesiol 2010;76(9):692-698.

26. Lim CM, Koh Y, Park W, Chin JY, Shim TS, Lee SD, et al. Mechanistic scheme and effect of "extended sigh" as a recruitment maneuver in patients with acute respiratory distress syndrome: a preliminary study. Crit Care Med 2001;29(6):1255-1260.

27. Talmor D, Sarge T, Malhotra A, O'Donnell CR, Ritz R, Lisbon A, et al. Mechanical ventilation guided by esophageal pressure in acute lung injury. N Engl J Med 2008;359(20):2095-2104.

28. Gattinoni L, Caironi P, Cressoni M, Chiumello D, Ranieri VM, Quintel M, et al. Lung recruitment in patients with the acute respiratory distress syndrome. N Engl J Med 2006;354(17):1775-1786.

29. Crotti S, Mascheroni D, Caironi P, Pelosi P, Ronzoni G, Mondino M, et al. Recruitment and derecruitment during acute respiratory failure: a clinical study. Am J Respir Crit Care Med 2001;164(1):131-140. 
30. Grasso S, Mascia L, Del Turco M, Malacarne P, Giunta F, Brochard $\mathrm{L}$, et al. Effects of recruiting maneuvers in patients with acute respiratory distress syndrome ventilated with protective ventilatory strategy. Anesthesiology 2002;96(4):795-802.

31. West JB, Dollery CT, Naimark A. Distribution of blood flow in isolated lung; relation to vascular and alveolar pressures. J Appl Physiol 1964;19:713-724.
32. Musch G, Harris RS, Vidal Melo MF, O'Neill KR, Layfield JD, Winkler T, et al. Mechanism by which a sustained inflation can worsen oxygenation in acute lung injury. Anesthesiology 2004;100(2):323-330.

33. Kacmarek RM, Kallet RH. Respiratory controversies in the critical care setting. Should recruitment maneuvers be used in the management of ALI and ARDS? Respir Care 2007;52(5):622-631; discussion 631-635.

This article is approved for Continuing Respiratory Care Education credit. For information and to obtain your CRCE

(free to AARC members) visit 